\title{
Experimental Study on Solar Air Collector with Internal Crimped Fins
}

\author{
Nguyen Xuan Lam ${ }^{1}$, Le Minh Nhut ${ }^{2, *}$ \\ ${ }^{1}$ Department of Thermal Engineering, Hoa Binh Xuan Loc Vocational College, Bienhoa, Viet Nam \\ ${ }^{2}$ Department of Thermal Engineering, Faculty of Vehicle and Energy Engineering, Ho Chi Minh City University of Technology and \\ Education, Ho Chi Minh, Viet Nam
}

Email address:

nhutlmahcmute.edu.vn (Le M. Nhut), xuanlame5218@gmail.com (N. X. Lam)

${ }^{*}$ Corresponding author

\section{To cite this article:}

Nguyen Xuan Lam, Le Minh Nhut. Experimental Study on Solar Air Collector with Internal Crimped Fins. International Journal of Energy and Power Engineering. Vol. 7, No. 2, 2018, pp. 19-26. doi: 10.11648/j.ijepe.20180702.11

Received: October 23, 2017; Accepted: February 1, 2018; Published: May 25, 2018

\begin{abstract}
This paper presented the results of a solar air collector with internal crimped fins. It consists of a flat plate collectors with seven internal crimped fins and has the total collection surface area of $2 \mathrm{~m}^{2}$. The investigation results indicate that the introduction of internal crimped fins can strengthen the convective heat transfer process and lessen the radiation heat loss, which contributes to efficiency improvement. In case the optimum number of for this study was seven crimped fins, The result of the air mass flow rate should be controlled in a range of $0.025-0.027 \mathrm{~kg} / \mathrm{s}$. The influence of internal crimped fins number, ratio between leght wing and fin pitch, as well as the air mass flow rate on the collector performance presented in this paper. The operating parameters such as the surrounding temperature, solar radiation intensity have significant influence on the temperature rise but have little influence on collector efficiency, which indicates that this kind of solar air collector could be applied in a wide range of geographical latitude.
\end{abstract}

Keywords: Air Collectors, Baffles, Collector Efficiency, Flat Plate Collector, Solar Air Heater, Solar Radiation

\section{Introduction}

At the beginning of the 21 st century the world is facing many problems to face. The rapidly growing population and rapid urbanization of the world are also factors that strongly influence the demand for energy. The critical issue is the crisis of energy, the depletion of resources and the environmental pollution that makes renewable energy use increasingly necessary. With the advancement of modern science and technology, people can exploit clean energy sources such as wind, solar, geothermal, tidal and biomass. In recent years, solar energy has become one of the most renewable, clean, endless and completely free renewable energy sources. Apply solar energy to human life as needs heating in winter, hot water for living. The application of solar energy to the drying technology such as agricultural products, wood drying, seafood drying as well as industrial products increasingly developed in the world to meet the needs of food preservation and improvement the number of products is increasing. One of the more popular solar-powered devices is the solar air collector. In recent years, there have been many studies in the world about increasing the efficiency of solar air collectors. In which focused primarily on studying the internal geometry of the collector is a method for increasing the efficiency of the collector. S. V. Karmare et al. [1] reported that artificial roughness on the underside of the absorber plate of the solar air heater enhances the rate of heat transfer from the absorber plate to the flowing air. The percentage increase in the heat transfer for $58^{\circ} \mathrm{C} \mathrm{rib}$ inclination plate over smooth plate is found to be about 30\%. M. S. Manjunath et al. [2] used for three dimensional CFD analysis were carried out to evaluate the influence of spherical turbulence generators on heat transfer enhancement of flat plate solar air heater. The maximum average percentage increase in thermal efficiency is found to be about $23.4 \%$ as compared to the base model for $\mathrm{D}=25 \mathrm{~mm}$ and $\mathrm{P} / \mathrm{D}=3$. The highest increase in the Nusselt number is found to be 2.5 times higher as compared to the base model for $\mathrm{D}=25 \mathrm{~mm}$ and $\mathrm{P} / \mathrm{D}=3$ at $\mathrm{Re}=23560$. Ha Chemi et al. 
[3] compared a fan-blown absorber plate with staggered rectangular plate fins. The improvement increases as the distance between consecutive rows of fins decreases. The thermal heat performance varies with the fluid mass flowrate, $\mathrm{G}=50 \mathrm{~kg} / \mathrm{h} . \mathrm{m}^{2}$, from $38.6 \%$ for the solar air heater collector with a plane absorber plate to $755 \%$ for the solar collector with a finned absorber plate, with rectangular fins, where the length, $\mathrm{L}$, is $10.0 \mathrm{~cm}$. El-Sawi et al. [4] compared the efficiency of flat plate, v-grooved and chevron pattern absorbers is also presented. The chevron pattern is found to have higher performance, reaching up to $20 \%$ improvement in thermal efficiency and an increase of $10^{\circ} \mathrm{C}$ in outlet temperature at some ranges of mass flow. B. M. Ramani et al. [5] discussed thermal performance of double pass solar air collector with porous absorbing material is $25 \%$ higher than that of double pass solar air collector without porous absorbing material and $35 \%$ higher than that of single pass collector. Tao Liu et al. [6] presented analytical and experimental studies on the thermal performance of cross-corrugated and flat-plate solar air heaters. The results the results have shown the v-groove absorber solar air collector has a significantly superior thermal performance to that of the flat-plate one, with $18 \%$ more achievable efficiency under the typical configurations and operating conditions. Wenfeng Gao et al. [7] reported the thermal performance of the type 2 heater is just slightly superior to that of the type 1 heater, both these cross-corrugated solar air heaters have a significantly superior thermal performance to that of the flat-plate one, with the achievable efficiencies of $58.9 \%, 60.3 \%$ and $48.6 \%$ for the type 1 , type 2 and flat-plate solar air-heaters, respectively, under the typical configurations and operating conditions. X. Q. Zhai et al. [8] reported experimental results indicate that the optimum inclination angle for the $\mathrm{SAC}$ is $45^{\circ}$, under which a maximum natural ventilation rate can be created. Also found is that there exists an appropriate channel length, about $1 \mathrm{~min}$ this study, beyond which the obtained heat and the natural ventilation rate cannot be increased drastically. A. Razak et al. [9] compared between the matrix absorber with flat plate absorber showed that the matrix setup with new recycling method mentioned pre-viously has able to achieveup to $75 \%$ efficiency against $60 \%$ for flat plate. Romdhane et al. [10] compared the effect of different baffle arrangement pattern in the solar air collector. The measurements showed that the efficiency reached $80 \%$ for the best type of chicanes, for an air flow rate of $50 \mathrm{~m} 3 / \mathrm{h} / \mathrm{m} 2$, and a temperature increase of $60^{\circ} \mathrm{C}$. Jianjun $\mathrm{Hu}$ et al. [11] discussed numerical analysis of mechanical ventilation solar air collector with internal baffles. The result of the air volume flow rate should be controlled in a range of $20-40 \mathrm{~m}^{3} / \mathrm{h} \cdot \mathrm{m}^{2}$ and the heat collecting efficiency achieveup to $60 \%$.

The research presented in this paper, with aims to study a mechanical ventilation solar air collector with internal crimped fins by our research group for the purpose of drying low temperature range from $50^{\circ} \mathrm{C}$ to $70^{\circ} \mathrm{C}$. The internal flow and heat transfer characteristic of this collector are analyzed. Moreover, the results are validated based on the experimental data. Then the parameters which influence collector efficiency obviously such as the fin number, fin pitch, leght wing. Besides, the operating conditions of air collector with internal crimped fins are also analyzed which can advance the current understanding of the fin-type collector and provide reference for design and optimization in the future.

\section{The Theoretical Basis}

The energy equations are as follows:

$$
\mathrm{H} \mathrm{R}_{\mathrm{b}} \mathrm{A}_{\mathrm{c}}=\mathrm{Q}_{\mathrm{U}}+\mathrm{Q}_{\mathrm{L}}+\mathrm{Q}_{\mathrm{S}}
$$

Where,

$\mathrm{H}$ : radiation energy sent per unit area of horizontal surface $\left(\mathrm{W} / \mathrm{m}^{2}\right)$

$\mathrm{Rb}$ : conversion factor from the horizontal plane to the inclined plane

Ac: surface area $\left(\mathrm{m}^{2}\right)$

$\mathrm{Q}_{\mathrm{U}}, \mathrm{Q}_{\mathrm{L}}$ and $\mathrm{Q}_{\mathrm{S}}$ respectively is useful energy, loss energy, Accumulated energy in composite materials, (W)

This study, useful energy can be expressed as:

$$
\mathrm{Q}_{\mathrm{U}}=\mathrm{mC}_{\mathrm{p}}\left(\mathrm{T}_{\text {out }}-\mathrm{T}_{\text {in }}\right)
$$

Where, $m$ represents the air volume flow rate $C_{p}$ represents the specific heat of air

T_out the outlet temperature, ${ }^{\circ} \mathrm{C}$

$\mathrm{T}$ in the inlet temperature, ${ }^{\circ} \mathrm{C}$

The heat collecting efficiency here is defined as:

$$
\eta=\frac{Q_{U}}{A_{c} H R_{b}}
$$

\section{System Description}

\subsection{Actual Device}

The self-designed solar air collector with total cavity size of $1 \mathrm{~m} \times 2 \mathrm{~m} \times 0.12 \mathrm{~m}$ is shown in Figure 1. The collector is equipped with numbers of internal crimped fins which divide the cavity into several chambers and form a serpentine flow channel. The air gets into the cavity from the bottom entrance and goes along the serpentine passage before coming out from the top exit. The crimped fins are designed to increase the dwell time of air in the heating chamber and improve the heat collecting efficiency ultimately. The bottom heat collection plate is coated with selective black coating with the solar radiation absorption rate up to $0.97( \pm 0.02)$. The periphery and bottom maintenance of the collector uses $50 \mathrm{~mm}$ thick polystyrene plate for efficient heat insulation. The top cover plate use ordinary $5 \mathrm{~mm}$ single glass. The crimped fins are made of corrugated aluminium to increase capacityofheat exchange surface and air distribution to maximize the area of heat exchange between the air and the absorber.

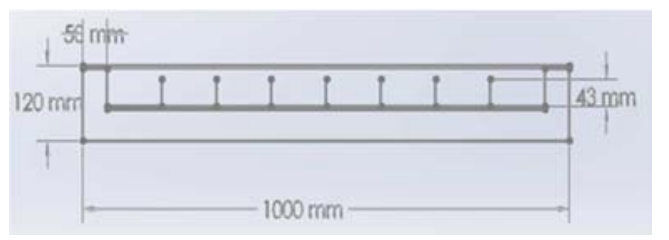

Figure 1. Dimensions of solar air collector. 


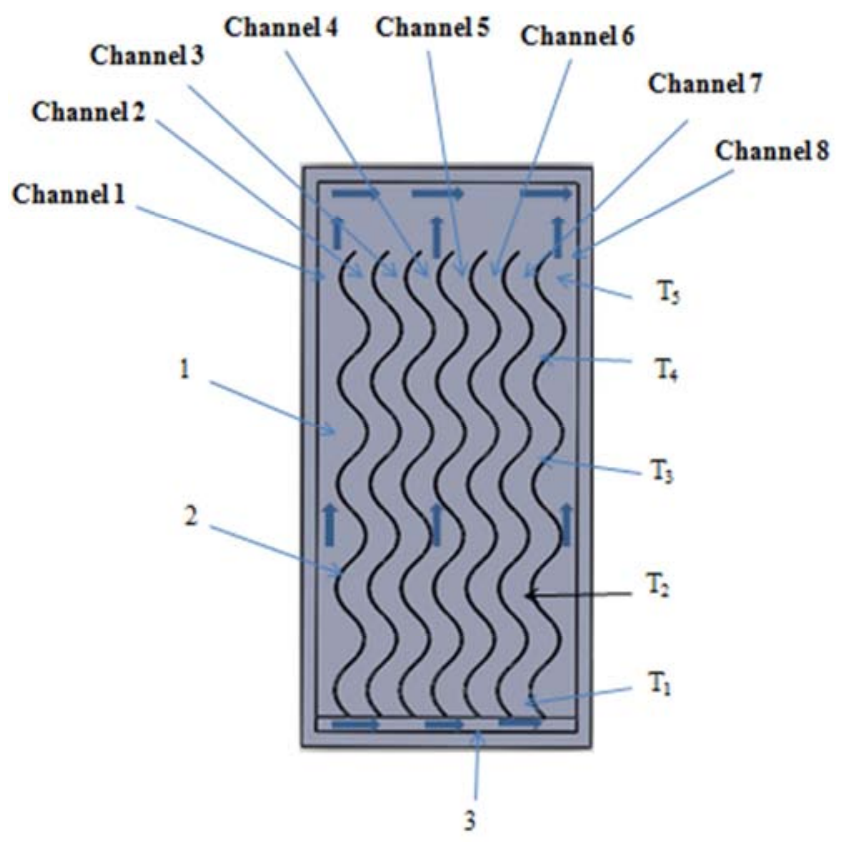

1-air channel; 2-Crimped fins; 3- Manifold

Figure 2. Diagram of solar air collector.

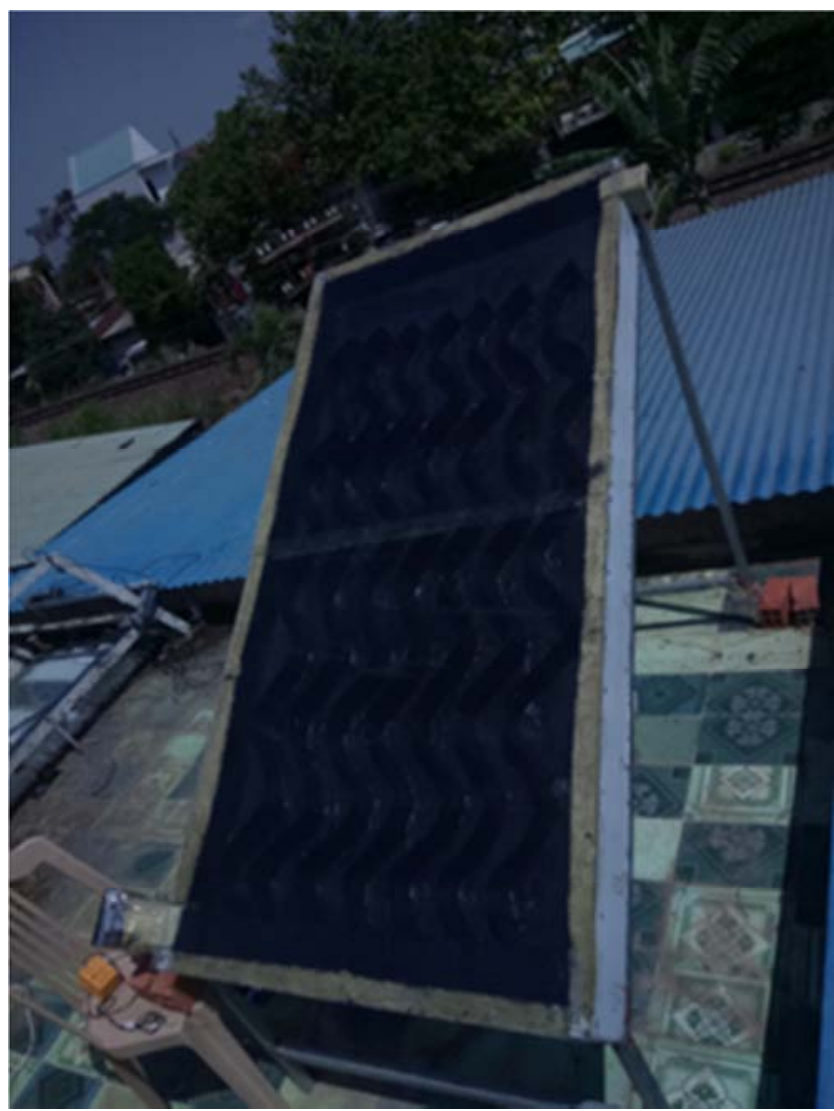

Figure 3. Diagram of the solar air collector with internal crimped fins.

\subsection{Experimental Procedure}

The local experiment was conducted in Bien Hoa, Dong Nai. The air mass flow rate used in this work between $0.01-0.04 \mathrm{~kg} / \mathrm{s}$. The parameters to be considered during the test include:solar radiation, inlet air temperature, outlet air temperature, heat absorber plate, temperature top glass cover, environmental temperature.

The data results will be recorded and processed by Excel software. Measurements system include: Adjustable air flow with dimmer $220 \mathrm{~V}-1000 \mathrm{~W}$ and axial fan with $22 \mathrm{~W}$ power factor, air flow $161.41 \mathrm{~m}^{3} / \mathrm{h}$. Solar radiation was determined by the TM-750 radiation meter with an error of $\pm 5 \%$, the speed and air flow through the receiver was determined by the HT- 81 wind velocity meter with an error of $\pm 3 \%$. The inlet temperature and outlet temperature, air temperature at the point in channel, absorption plate temperature and ambient temperature are determined by the AmpE VC3267 with error of $\pm 1.0 \%$.

Parameters are measured every 5 minutes. The experiment was carried out on September 20, 2017 to on February 5, 2018. Air is circulated for $30 \mathrm{~min}$ prior to the period in which data are taken. The experiment was carried out at 7 am and ended at 5 pm daily.

\section{Results and Discussion}

The Figures 4 shows two values for the intensity of solar radiation and the outlet temperature of air independent time. The highest the outlet temperature is $78.8^{\circ} \mathrm{C}$, corresponding to a radiation intensity of $900 \mathrm{~W} / \mathrm{m}^{2}$ in the period from 11 hours to 12 hours. The lowest output temperature is about $40^{\circ} \mathrm{C}$ with the radiation intensity of $200 \mathrm{~W} / \mathrm{m}^{2}$.

Mechanical ventilation solar air collector have seven fins and 8 channel for the passage of air. The Air through the manifold before entering theair channel to distribute the air flow evenly in the channels in order to maximize the heat exchange surface with the absorber to improve the heat recovery efficiency. The results shown in Figure 5 indicate that the air temperature in the respective channels and the temperature rise from the beginning to the end of the channel before the air leaves the collector. This demonstrates that the air in the collector distributes air uniformly in the channels, resulting in a uniform temperature from channel 1 to chanel 8.

Figures 6 and 7 shows the greater ratio of the leght wings and the fin pitch along with the less density of wave results in the lower of the heat recovery efficiency. The reason is that the air moving through channels forms air vortex in crimped fins. As a result, the air remaining in the collector to get the heat will cause increased convective heat loss as well as pressure loss. However, the less ratio of the leght fin and the fin pitch along with the limited density of fin reduces the time the air through the collector and limits the turbulent flow, which decreases convection heat transfer and absorber plate. In case the ratio is 1, the crimped fins become is flat fin, the air is distributed evenly in the channels, but the air flow were not create disturbances in the channel leads to less convection heat exchange between the air and the collector. In the case of dimensions fin pitch $(\lambda)$ are $178 \mathrm{~mm}$, the length of wing (L) are $210.40 \mathrm{~mm}$, radius of crimped (R) are $50 \mathrm{~mm}$ corresponding the maximum efficiency. 


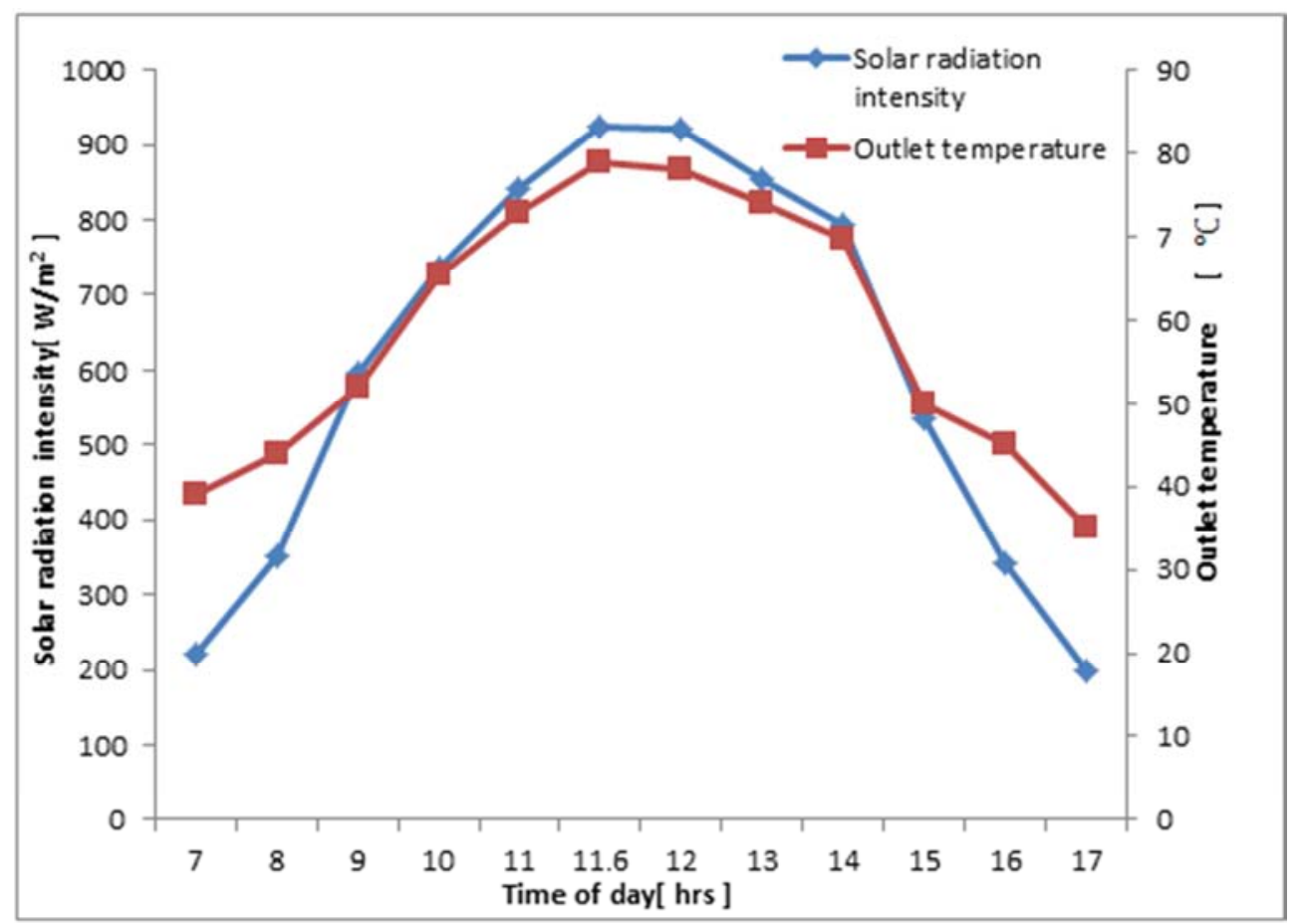

Figure 4. Influence of solar radiation intensity on the outlet temperature.

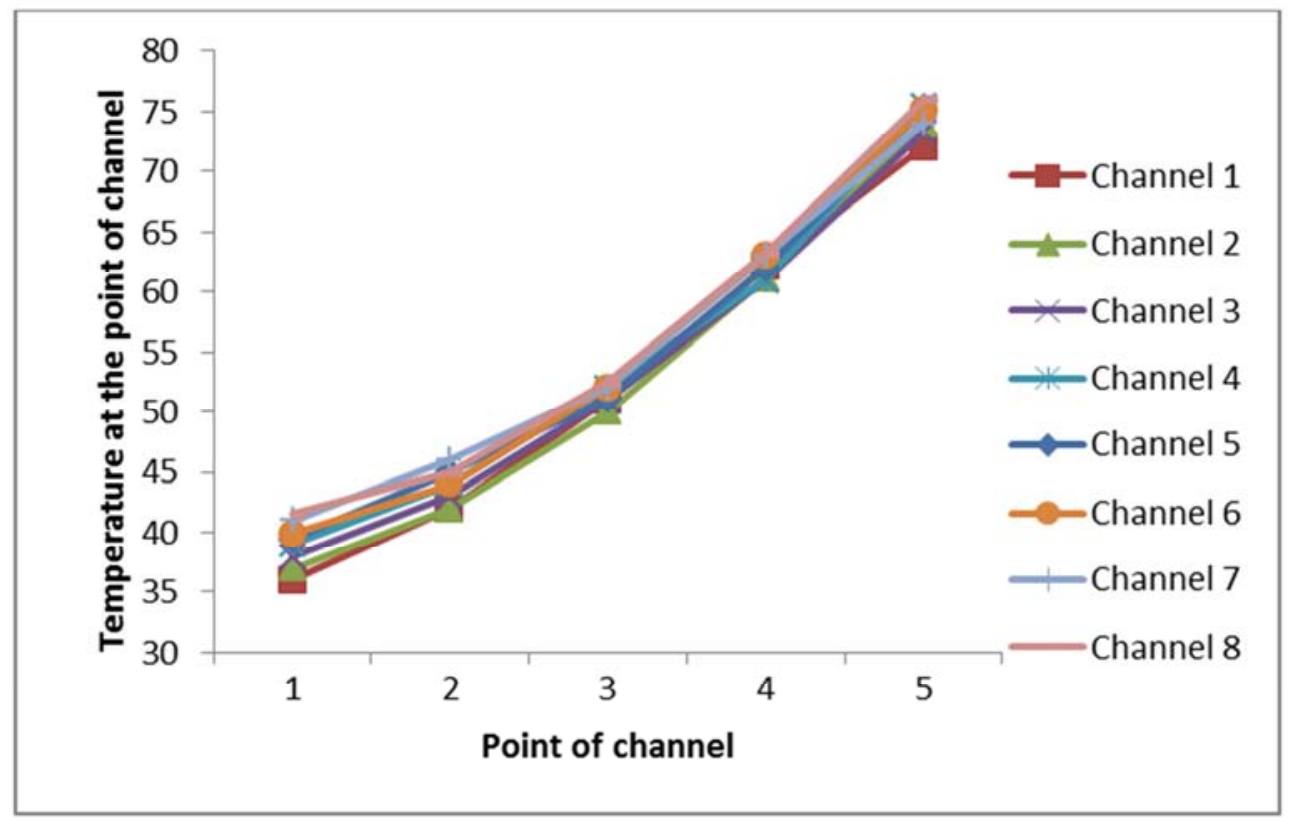

Figure 5. Air temperature at the point in channel.

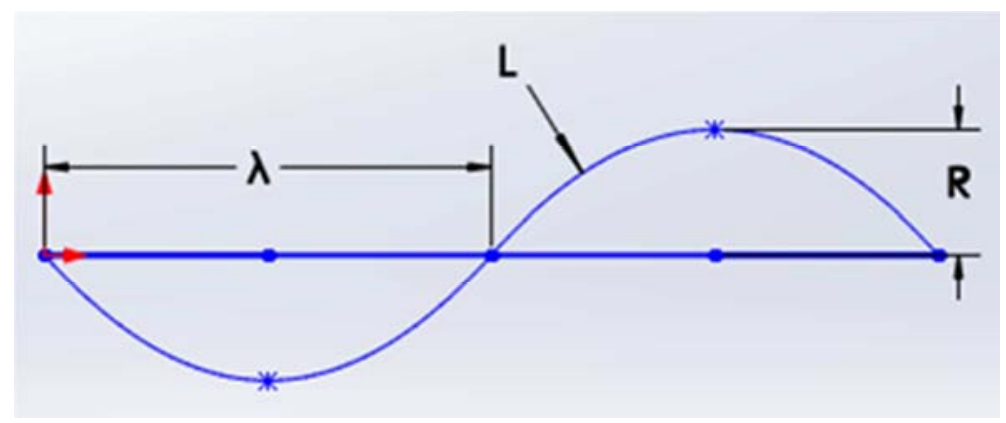

Figure 6. Schematic diagram of crimped fins L-leght wing; $\lambda$-fin pitch; $R$-radius of fins. 


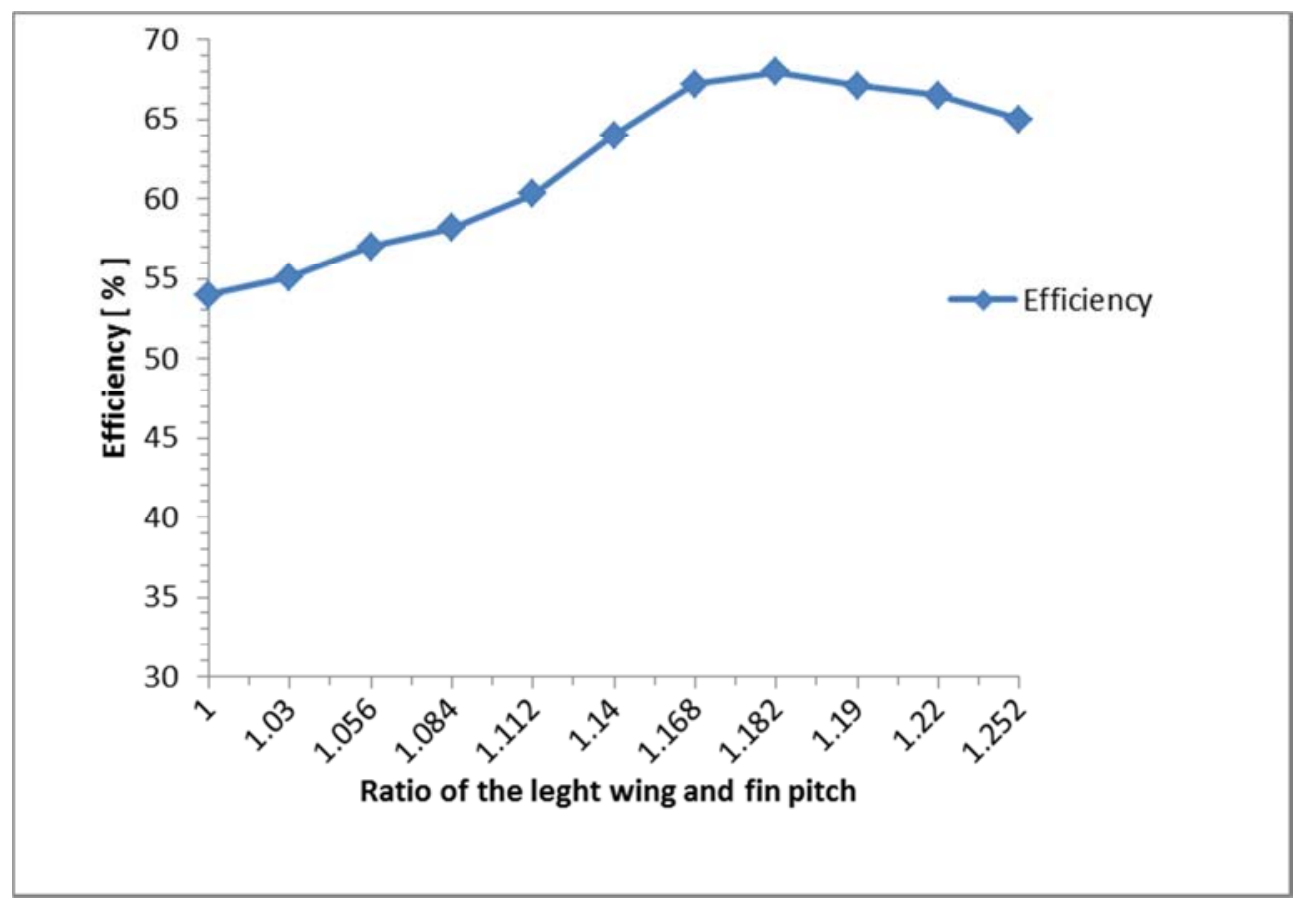

Figture 7. Influence of the ratio leght wing and fin pitch on the heat collecting efficiency.

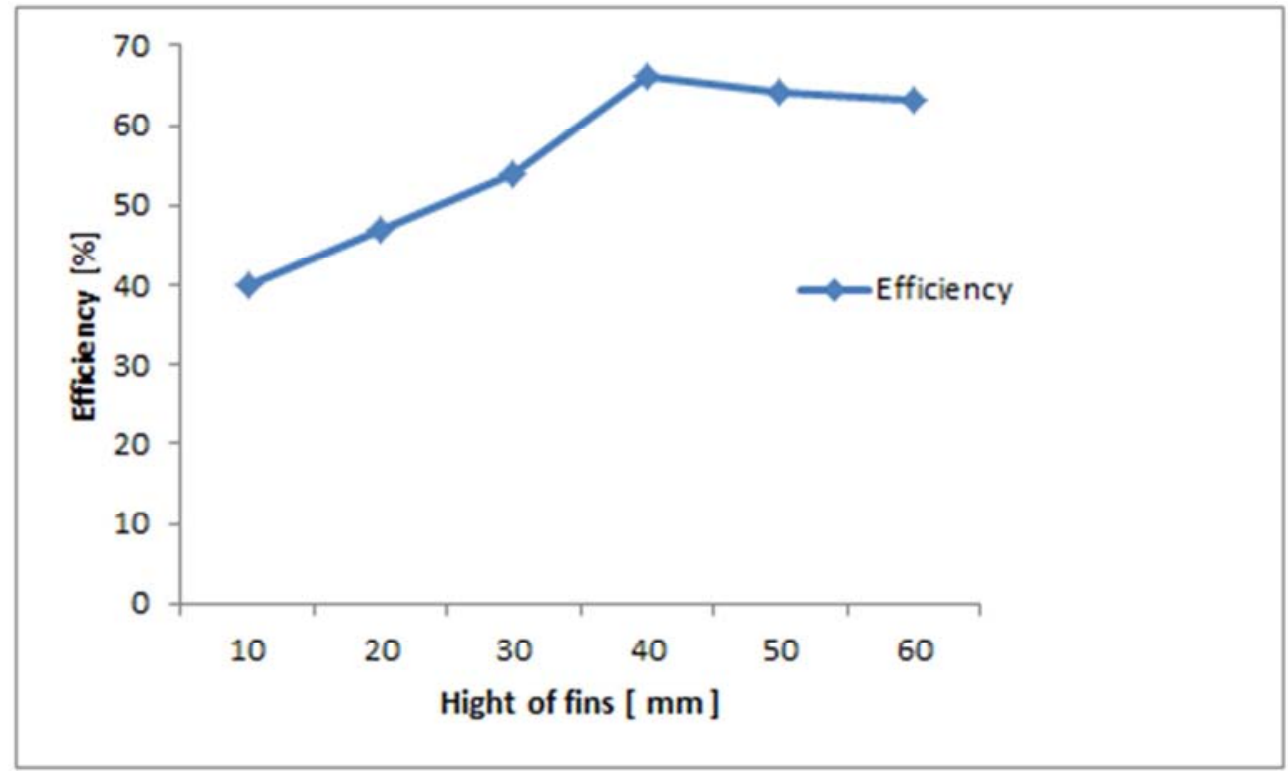

Figure 8. Influence of fin hight on the heat collecting efficient.

Figure 8 shows the effect of fin height on the collector's heat recovery efficiency. Experimental results indicate that the case height is $43 \mathrm{~mm}$, the heat collector efficiency is higher than the other cases. Continue to increase the height of fins until it is equal to the air gap corresponding the heat collecting efficiency decrease. When the height fin is equal to the air distance leading to air contact with the glass increases the convection heat exchange between the air and the glass will cause increased heat losses. But if the fin height is too low, the fin are not sufficiently sized to divide the air flow in the collector as well as the ability to create turbulent, resulting in poor convection heat exchange between the air and the collector.
Figure 9 reflects the influence of the number of the fins and the volume air on the heat collecting efficiency. As the increasing of volume flow rate, the heat collecting efficiency and flow resistance rise, while the outlet temperature decreases. Therefore, a balance should be found for optimum performance. For the considered solar air collector with crimped fin, the air volume flow rate should be controlled in a range of $0.025-0.027 \mathrm{~kg} / \mathrm{s}$. In the case of this experimental study the air volume rate through collector was $0.027 \mathrm{~kg} / \mathrm{s}$ and the number of fins was 7 fins, the heat recovery efficiency was $67 \%$ higher than the other cases. In terms of the fin be putted in located at least, it will be impact on decreasing channels of the air diffusion in the collection, the 
low air flow capacity and low utilization of maximum heat exchange area between air and surface absorption. Therefore, the efficiency is over $67 \%$ and it is higher than other cases. In case the number of fin arranged in the collector is low, so air flow in channels decreases. For this reason, the uneven distribution of air flow in the collector. After that a turbulent flow of air move in collector on the decrease, so heat exchanger efficiency both of air and collector significant reduction. As the result, convection heat exchangers between the air and the fins and the absorber plate are reduced, which is also the cause of radiation damage. However, the rate of fin is hight in collector, the absorption area of the solar radiation absorbed was reduced and the air conduits are more likely to cause pressure losses.

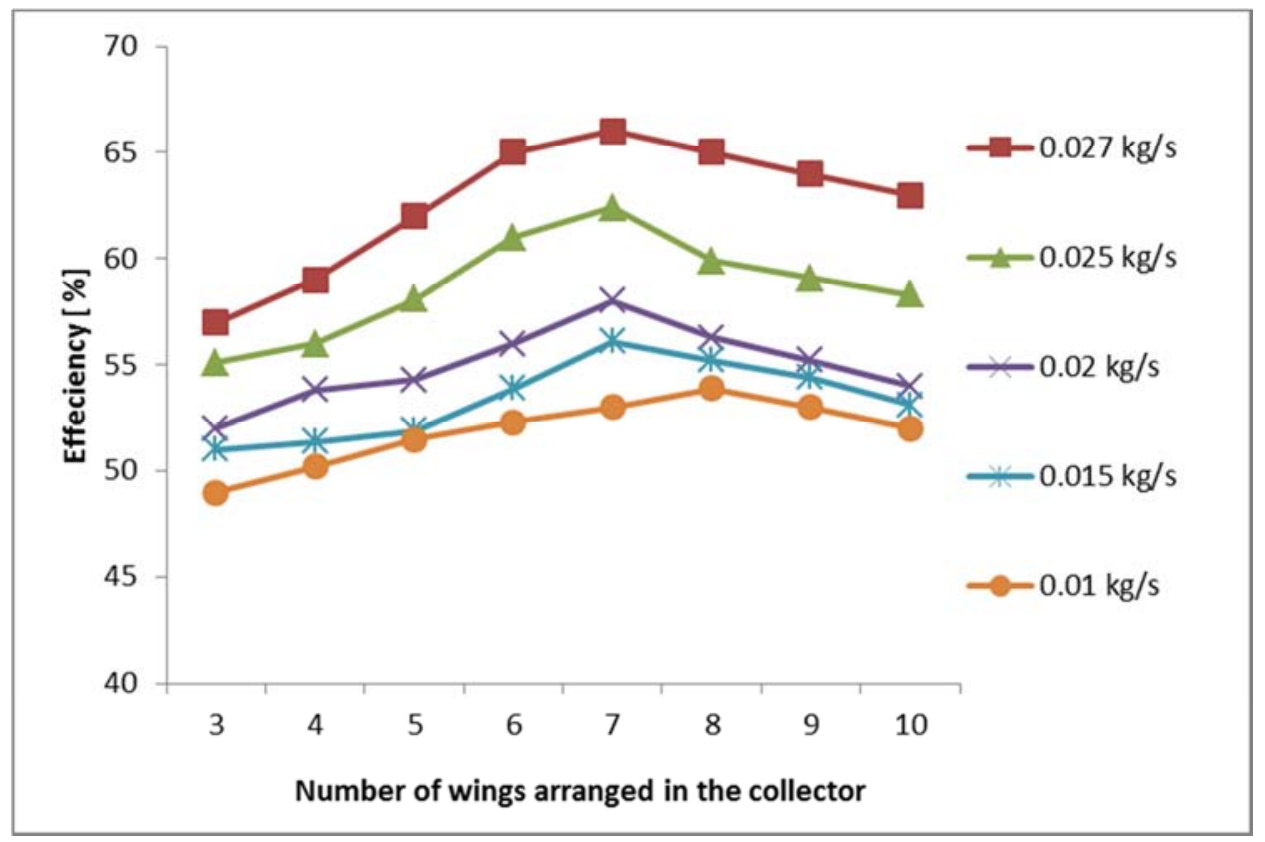

Figure 9. Variations of heat collecting efficiency at different volume flow rate and numer fin.

Figure 10 and Figure 11 shows for the considered Solar air collector with internal crimped fins, the air volume flow rate should be controlled in a range of $0.025-0.027 \mathrm{~kg} / \mathrm{s}$. The operating parameters such as the solar radiation intensity and the surrounding temperature have significant influence on the temperature rise, but have little influence on the heat collecting efficiency. It indicates that this kind of solar air collector with internal crimped fins could be applied in a wide range of areas.

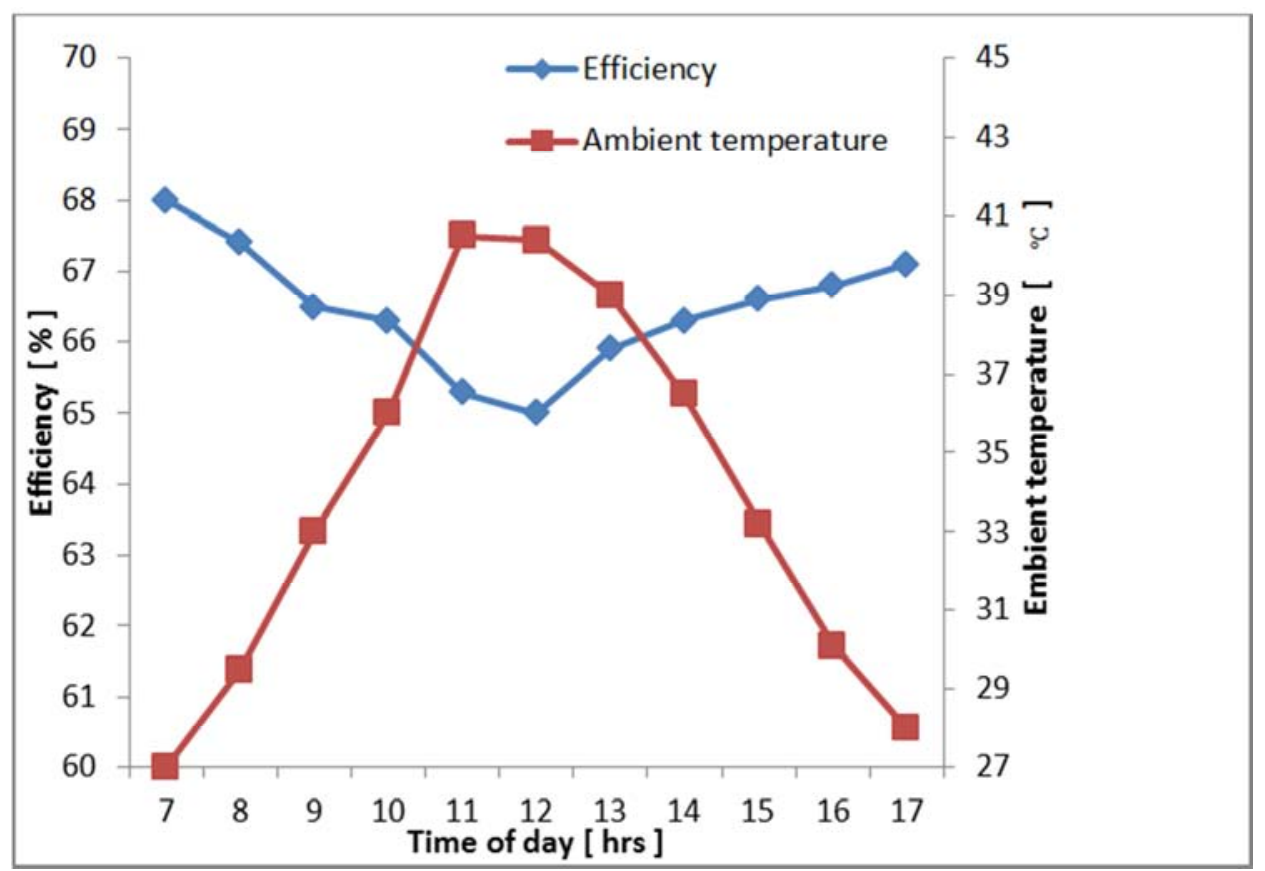

Figure 10. Influence of ambient temperature on performance. 


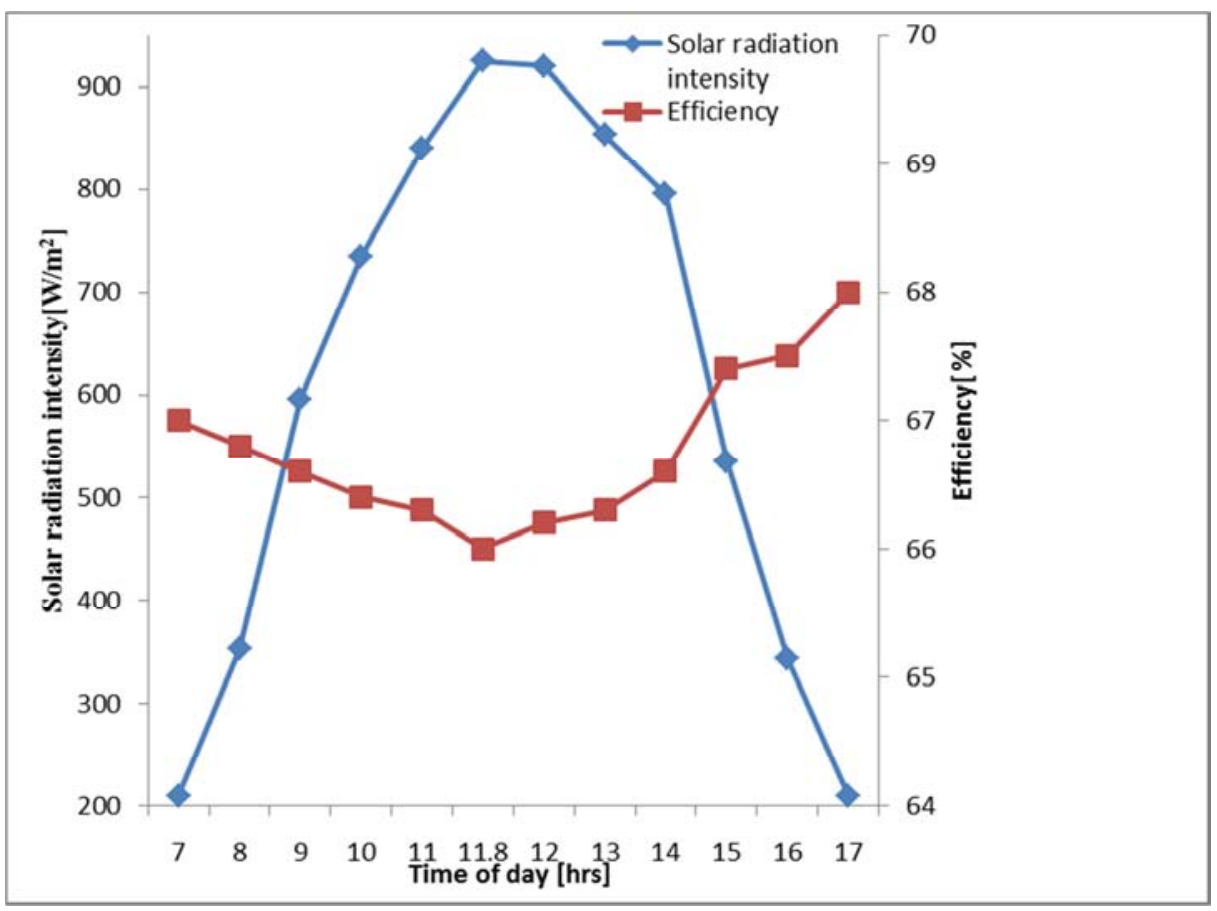

Figure 11. Influence of solar radiation intensity on performance.

\section{Conclusions}

In this paper, the internal crimped fin-type solar collector is analyzed and evaluated based on the results verified and it is been through an experimental system. The results can be drawn from the studies. This systerm is designed with internal longitudinal wings extends the air time in the collector, after that it have been enhances turbulent air flow and contributes to improved receiver performance. The vortices are created by the geometry of the wings, causing air to be trapped in there and forming some high temperature regions, for this reason, it is leaded to large heat losses. So we should have solutions to reject vortices, then collector have effective way to improve recovery efficiency. The convective heat transfer is mainly responsible for the total heat loss. Consequently, design should be undertaken to reduce convective heat losses, such as ration between the leght wings and fin pitch, hight of fin, number fin, the volume air rate etc... There exists an optimal fin number. In this case, The collector have seven fins. The volume air rate regulation is an important indicator for evaluating the collector's performance and is of great relevance to heat recovery, temperature rise and airflow resistance. When the volume air rate increases, the heat recovery efficiency and rising flow resistance increase, while the outlet temperature decreases. Therefore, it is necessary to have a balance to achieve optimum performance. For solar air collectors to be considered, the air mass flow rate must be controlled in a range of $0.025-0.027 \mathrm{~kg} / \mathrm{s}$ to ensure the outlet temperature serves the intended use. Performance parameters such as solar radiation intensity and ambient temperature have a significant effect on the increase in temperature but little effect on heat recovery efficiency. From the experimental results that can be concluded above, the solar air collector with internal crimped fin can be applied in a wide range of fields.

\section{References}

[1] S. V. Karmare, A. N. Tikekar, "Analysis of fluid flow and heat transfer in a rib grit roughened surface solar air heater using CFD”, Solar Energy, 84, 2010, pp. 409-417.

[2] M. S. Manjunath, K. Vasudeva Karanth, N. Yagnesh Sharma "Numerical Analysis of the Influence of Spherical Turbulence Generators on Heat Transfer Enhancement of Flat Plate Solar Air Heater", Solar Energy, 131, 2016, pp. 47-60.

[3] A. Hachei, "Thermal performance enhancement of solar air heaters, by a fan blown absorber plate with retangular fins ", In ternational journal of energy research, 19, 1995, pp. 567-578.

[4] A. M. El-Sawi, A. S. Wifi, M. Y. Younan, E. A. Elsayed, B. B. Basily, "Application of folded sheet metal in flat bed solar air collectors", Applied Thermal Engineering, 30 2010, pp. 864 871.

[5] B. M. Ramani, A. Gupta, R. Kumar, "Performance of a double pass solar air collector”, Solar Energy, 84, 2010, pp19291937.

[6] Tao Liu, Wenxian Lin, Wenfeng Gao, "A Parametric Study on the Thermal Performance of a Solar Air Collector with a V-Groove Absorber" International Journal of Green Energy, 2007, pp. 601-622.

[7] Wenfeng Gao, Wenxian Lin, Tao Liu, Chaofeng Xia, "Analytical and experimental studies on the thermal performance of cross-corrugated and flat-platesolarairheaters", Applied Energy, 84, 2007, pp. 425-441. 
[8] X. Q. Zhai, Y. J. Dai, R. Z. Wang, "Experimental investigation on air heating and natural ventilation of a solar air collector", Energy and Building, 37, 2005 pp. 373-381.

[9] A. A. Razak, Z. A. A. Majid, W. H. Azmi, M. H. Ruslan, Sh. Choobchian, G. Najafi,"Review onmatrix thermal absorber designs for solar air collector" Renewable and Sustainable EnergyReviews, 64, 2016, pp. 682-693.
[10] Ben Slama Romdhane, "The air solar collectors: Comparative study, introduction of bafflesto favor the heat transfer", Solar Energy, 64, 2007, pp. 139-149.

[11] Jianjun Hu, Xishan Sun, Jinliang Xu, "Numerical analysis of mechanical ventilation solar air collector with internal baffles", Solar Energy, 62, 2013, pp. 230-238. 